\title{
EXPERIMENTAL INVESTIGATION OF HEAT TRANSFER IN TWO-PASS COOLANT PASSAGES WITH RIBS AND FILM COOLING HOLE EJECTION
}

\author{
D. Chanteloup \\ A. Bölcs
}

\author{
I denis.chanteloup@epfl.ch \\ I albin.boelcs@epfl.ch
}

\author{
I EPFL - LTT - 1015 Lausanne - Switzerland \\ / EPFL - LTT - 1015 Lausanne - Switzerland
}

\section{ABSTRACT}

A study of flow in two stationary models of two-pass internal coolant passages is presented, which focuses on the heat transfer characteristics in the two-pass coolant channel.

Heat transfer measurements were made with a transient technique using thermochromic liquid crystal technique to measure a surface temperature. The technique allows full surface heat transfer coefficient measurements on all the walls.

The coolant passage model consisted of two square passages, each having a 20 hydraulic diameter length, separated by a rounded-tip web of 0.2 passage widths, and connected by a sharp 180 deg bend with a rectangular outer wall. Ribs were mounted on the bottom and top walls of both legs, with a staggered arrangement, and at $45 \mathrm{deg}$ to the flow. The rib height and spacing were 0.1 and 1.0 passage heights, respectively. The measurements were obtained for Reynolds numbers of 25000 , 50000 and 70000 . One geometry is equipped with extraction holes to simulate holes for film cooling. Two series of holes are placed solely in the bottom wall, 4 holes are located in the bend, and 12 in the downstream leg. The global extraction through the holes was set to $30 \%, 40 \%$ and $50 \%$ of the inlet massflow. This paper presents new measurements of the heat transfer in the straight legs, and in the bend of the passage. It shows the influence of Reynolds number and extraction on full surface measurements and area averaged results.

\section{INTRODUCTION}

For the design of gas turbine blades, a detailed knowledge of the physical phenomena in the passage is necessary. To improve the performance of the CFD codes, a validation of the predictions is necessary, and detailed measurements of the flow structure and heat transfer distribution in the passages are required for comparison.

Rib arrays inside an internal cooling channel are often used in heat exchanger systems to enhance the heat transfer rate. Heat transfer characteristics have been reported in $45 \mathrm{deg}$ rib arrangement in literature. Several references describe area averaged results, performed mainly with thermocouples
(Mochizuki et al. [1] and Han et al. [2]). Correlations presented in Han et al. [3] and Han et al. [4], have been built in single pass channel for several Re numbers and geometrical characteristics. Detailed full surface heat transfer measurements have also been published (Wang et al. [5], Rau et al. [6]).

Heat transfer data in internal coolant channels with film cooling extraction is also of great importance to the design of a cooling system. Byerley et al. [7] measured local heat transfer coefficients around the entrance to a normal hole. They reported considerable heat transfer coefficient variations (six times the plain duct local value) around the entrance. Shen et al. [8] noted that in the presence of normal ribs, the heat transfer in the vicinity of the holes was increased by about $25 \%$. Thurman et al. [9] focused on varying bleed rates and rib placement relative to hole locations.

Although detailed heat transfer measurements in coolant channels are available in literature, the combination of flow measurements and heat transfer distribution in ducts with cooling holes has not been described. Rau [10] and Chanteloup et al. [11] described the flow and heat transfer combination in fully developed regions of channel with $45 \mathrm{deg}$ rib arrangement. In Chanteloup et al. [12], Chanteloup et al. [13] and Chanteloup et al. [14], the particle-image-velocimetry (PIV) measurement method was employed for the investigation of the flow field in models with film cooling holes and turning vane. In combination with the present paper, they give a description of both heat transfer and flow measurements in two-pass square channels with $45 \mathrm{deg}$ rib arrangements.

In the present study, full surface heat transfer measurements were made on all the outer walls of the channel. The transient liquid crystal technique described in Wang et al. [15], is suitable for full surface heat transfer measurements in regions with high heat transfer gradients. Because in long test channels, the gas temperature is not a perfect step, the Duhamel theorem was used to process the gas temperature (Ekkad et al. [16]). The information was processed with a full digital system as presented in Vogel et al. [17]. 
This paper presents results from the Brite-Euram project, for Internal Cooling of Turbine Blades (ICTB). The specific objectives of the present paper are to present measurements of the heat transfer in the straight leg, and in the bend of the passage, and to show the influence of Reynolds number and extraction on full surface and area averaged results.

\section{EXPERIMENTAL SETUP}

\section{Test Facility}

A sketch of the test section and the channel geometry characteristics are given in Figure 1 Air was the working medium and was supplied by a continuously running compressor. The air enters the settling chamber with an inner diameter of $600 \mathrm{~mm}$ via a $150 \mathrm{~mm}$ tube and a conical entrance section with an angle of $30 \mathrm{deg}$. The settling chamber is equipped with a combination of perforated plates, honeycombs and meshes to reduce unsteadiness and swirl in the flow. A bell mouth entry leads the air from the settling chamber to the test channel. The settling chamber outlet is equipped with heaters. A turbulence grid is placed downstream of the heaters during the heat transfer measurements to reach the same turbulence level at the channel inlet as for flow measurements, which are presented in Chanteloup et al. [13].

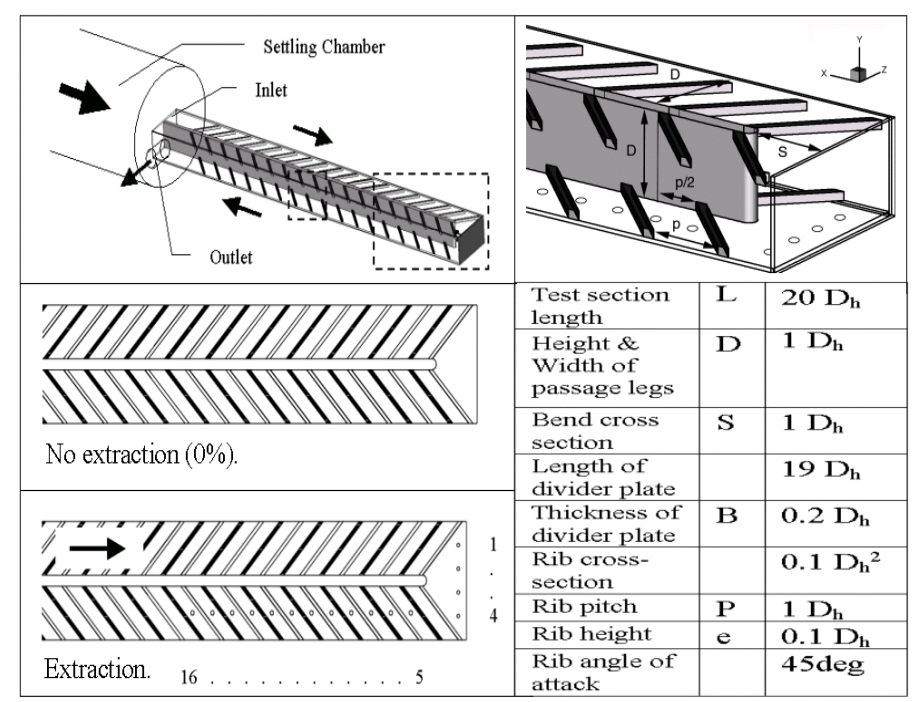

Figure 1: The internal coolant passage test facility and inlet region details.

The test section is a two-pass, cooling passage model of a gas turbine blade. The ribs in the bend region and the dimensions of the bend are shown in Figure 1. Eighteen ribs are mounted on each of the top and bottom walls in each of the upstream and downstream passages of the model $(18 * 4)$.

Another test configuration, which had the same geometrical characteristics as the first one, was equipped with two series of holes for film cooling simulation. The total mass flow through 16 holes was adjusted to $30 \%, 40 \%$ or $50 \%$ of the test model inlet massflow. The high extraction massflow was chosen to investigate the influence of holes on the flow. It has been chosen to place 16 holes solely in the bottom wall, with a hole pitch to hole diameter ratio of 6 . The first series of holes is placed in the bend region, $0.2 D_{H}$ from the end wall to simulate tip blade film cooling. Four $0.073 D_{H^{-}}$diameter holes $(7.3 \mathrm{~mm})$ are equally displaced between the leading and the trailing outer walls (Figure 2). Twelve $0.082 \mathrm{D}_{H^{-}}$-diameter holes $(8.2 \mathrm{~mm}$ ) are located downstream of the bend, the rib pitch to hole pitch ratio is set to 2 , in order to have two holes per rib-pitch. This series is situated on the bottom wall downstream leg centerline $(Z=-0.6)$. Note that the extraction massflow and the hole to rib placement were not chosen to quantify or optimize a specific geometry, but to characterize the effect of holes on the flow and on the heat transfer distribution.

\section{Flow conditions, measurement program and coordinate systems}

The measurements were obtained with air as working medium, at three flow Reynolds numbers of 25,000, 50,000, and 70000 (corresponding to bulk velocities: $U b=3.79 \mathrm{~m} / \mathrm{s}$, $7.58 \mathrm{~m} / \mathrm{s}, 10.61 \mathrm{~m} / \mathrm{s})$, at the entrance of the test section. The Reynolds number are based on the $0.1 \mathrm{~m}$ hydraulic diameter with an air temperature of $18 \mathrm{C}$. Upstream of the test-rig, the mass flow is measured by means of a $5864 \mathrm{~S}$ Brooks flow meter with a 1-percent accuracy. The turbulence level is approximately 3 percent at the model inlet.

Extraction through the holes is adjusted by increasing the inner configuration pressure level. A butterfly valve, placed far downstream of the test section exit, adjusts the backpressure. A second 5864S Brooks flow meter, measures the exit massflow downstream of the butterfly valve, which is adjusted to obtain the desired extraction. Extractions through each hole have been characterized by hole velocity measurements. Detailed description of the massflow through the holes is given in Chanteloup et al. [13].

Full surface heat transfer measurements in the passage have been obtained in the bend, upstream $\left(6 D_{H}\right)$ and downstream $\left(6 D_{H}\right)$ of the $180 \mathrm{deg}$ bend. Additional measurements have been obtained $10 D_{H}$ downstream of the bend. All the five outer walls of the test section were measured simultaneously. On the two ribbed walls, measurements were performed on the surfaces between two consecutive ribs, and on the bend surfaces.

The definition of the coordinate systems in the test facility is shown in Figure 2. A Cartesian coordinate system is used in the test channel. The origin is set on the bottom wall at the centre of the rounded end of the divider plate. The Cartesian system is composed of $X-, Y-, Z$-axis. $X$ is defined as positive in the streamwise direction of the flow downstream of the bend exit, $Y$ is defined positive vertically upwards in the horizontal test section orientation, and $Z$ is defined positive in the upstream leg. For clarity reasons, the accumulated length $l$ was also used in some of the plots presented in the following chapters. The accumulated duct length is defined as the accumulated distance relative to the channel end wall in the turning region. The accumulated distance is made nondimensional with the duct hydraulic diameter. $l$ starts at $-20 D_{H}$ 
at the channel entry section, continues through to $0 D_{H}$ at the opposite end wall and end at $+20 D_{H}$ at the channel exit section.

a) Side view of the channel (perpendicular to $X$-Y plane)

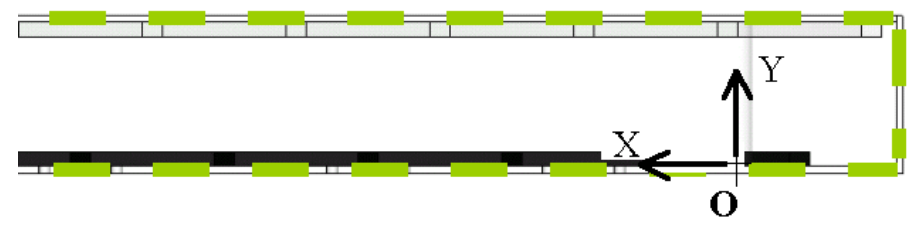

b) Front view of the channel (perpendicular to $X-Z$ plane)

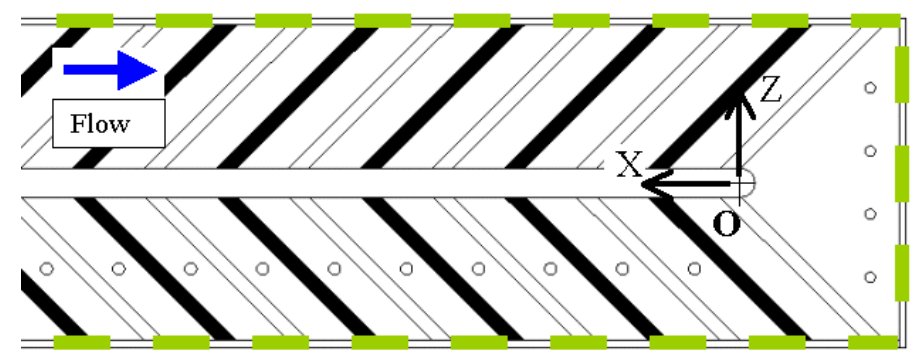

: Measured walls coated with Black paint and TLCs.

Figure 2: Measurement sections and coordinate systems

Table 1 summarises the measurement program in a test matrix. All the four extractions were measured for all the three Reynolds numbers. The test rig did not allow to enough decrease the static pressure downstream of the test model to allow measurements at $\mathrm{Re}=25000$ and $30 \%$ extraction.

\begin{tabular}{|c|c|c|c|}
\hline \multirow{2}{*}{$\mathcal{C}_{\text {extrac }}$} & \multicolumn{3}{|c|}{ Re number } \\
\cline { 2 - 4 } & 25000 & 50000 & 70000 \\
\hline $0 \%$ & $\mathrm{X}$ & $\mathrm{X}$ & $\mathrm{X}$ \\
\hline $30 \%$ & & $\mathrm{X}$ & $\mathrm{X}$ \\
\hline $40 \%$ & $\mathrm{X}$ & $\mathrm{X}$ & $\mathrm{X}$ \\
\hline $50 \%$ & $\mathrm{X}$ & $\mathrm{X}$ & $\mathrm{X}$ \\
\hline
\end{tabular}

Table 1: Measurement program

\section{Heat transfer measurements}

For the present study, transient heat transfer experiments were performed using liquid crystals to determine the surface temperature. The transient technique is well described in Wang [18]. The transient liquid crystal technique consists of monitoring the surface temperature evolution in time with a step change in the gas temperature. Eleven fine, fast response, mesh heaters were fitted to the duct inlet to produce the step change in gas temperature. This heater comprises a mesh of stainless steel wires, $40 \mu \mathrm{m}$ in diameter woven at a pitch of approximately $100 \mu \mathrm{m}$, with an open area of $38 \%$ (see Wang et al. [15] for more details). The meshes were connected in series to the $10 \mathrm{~kW}$ power supply $(256 \mathrm{~A}, 40 \mathrm{~V})$. Figure 3 shows a typical variation of temperature with time in the test channel. At the inlet, the heaters provide a step change in temperature of $75 \%$ and $99 \%$ of the total temperature increase, in $0.4 \mathrm{~s}$ and $0.6 \mathrm{~s}$ respectively. The temperature distribution across the inlet section is constant with a spatial variation of less than $3 \%$ of the total temperature step.
In the present experiments, the heat transfer coefficient $\alpha$ is obtained by using the 1D unsteady heat conduction equation, and treating the wall material as "semi-infinite" which limits the allowable measurement time. Vogel et al. [19] showed, that the maximum allowable measurement time can be calculated from $t_{\max }=L^{2} /(0.25 \cdot \Lambda)$, where $L$ is the model thickness and $\Lambda$ the thermal diffusivity of the model material. In the present study, a $5 \mathrm{~mm}$ thick Plexiglas model was used to obtain good optical properties for PIV experiments; the maximum allowable time is $t=64 \mathrm{~s}$, which is longer than the typical measurement duration of $38 s$.

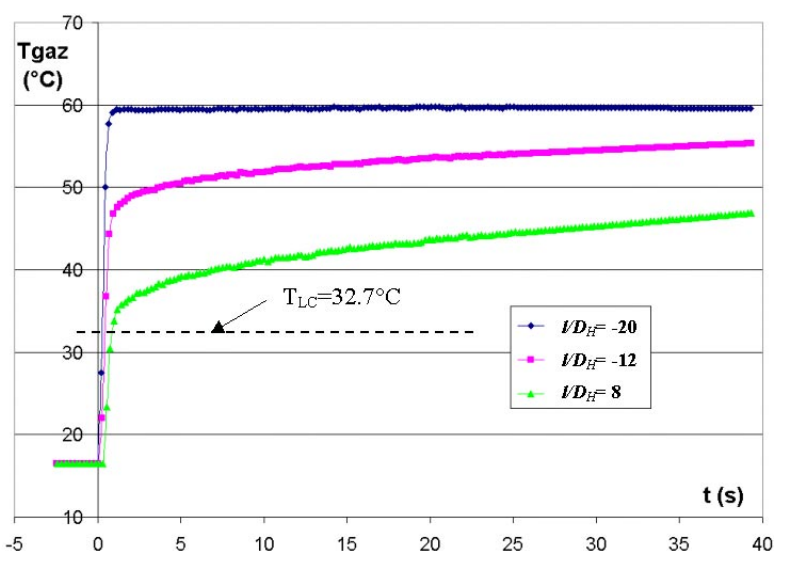

Figure 3: Gas temperature increase at different l/D locations for heat transfer post processing

The transient heat transfer measurement method consists of monitoring the surface temperature evolution by acquiring the colour signal of a liquid crystal coating applied on the test section. By using a single layer of narrow-band thermo-chromic liquid crystals (Hallcrest BM/R30.5C0.7W/C17-10), the evolution of the local surface temperature $T_{\text {wall }}(y, z, t)=T_{L C}$ is obtained from a hue capturing technique. Several miniature colour CCD cameras mounted around the test section record the colour change of the liquid crystal coating. The video signal of each view is digitally stored on DV (Digital Video) tapes. The use of the DV format storage ensures precise colour image signal restitution at constant image frequency and without any noise generation. Video sequences of each camera are transferred subsequently to a computer where the image processing and the data reduction are performed.

The liquid crystals are painted directly on the channel inner Plexiglas surface. A black paint coating covers the liquid crystals to provide a good colour background for image acquisition. A validation procedure was conducted to ensure that the black coating doesn't affect the quality of the results.

The 1-D transient conduction equation, with classical initial conditions and boundary conditions on the test surface, is used to obtain the non-dimensional temperature at the convective boundary surface:

$$
\frac{T_{\text {wall }}(t)-T_{i}}{T_{G}-T_{i}}=1-\exp { }^{\alpha^{2} \frac{\Lambda \cdot t}{\lambda^{2}}} \operatorname{erfc}\left(\frac{\alpha \sqrt{\Lambda \cdot t}}{\lambda}\right)
$$


The initial temperature $T_{i}$ was measured in the Plexiglas model, after a thermal balance was reached between the gas temperature and the model outer surface temperature.

Thermocouples were placed along the channel to measure the gas temperature. They were located in the centre of one of the secondary flow vortex ( $Y=0.67, Z=0.43$ in the upstream leg). Tests based on numerical simulations showed that at this cross-section location, the gas temperature is closer to the bulk temperature than the centreline temperature, with $\left|T_{\text {measured }}-T_{\text {bulk }}\right|<1^{\circ} \mathrm{C}$ along the entire channel. The thermocouples were separated $1 D_{H}$ from another in the region of interest. A linear interpolation of the gas temperature in $X$ direction was performed for every location between the thermocouples.

The use of heater grids yields a double dependence of the gas temperature on time and $X$-location (see Figure 3). Downstream of the inlet, due to heat exchange the temperature increase is no longer a step. For a given $X$, the gas temperature is an increasing function of time (Ekkad et al. [16]). It can be shown that, when the gas temperature change can be expressed as series of $n$ summed step functions, the Plexiglas surface temperature $T_{\text {wall }}(t)=T_{L C}$ is

$$
T_{\text {wall }}(t)=T_{L C}=T_{i}+\sum_{j=1}^{n}\left(T_{G, j}-T_{G, j_{-} 1}\right) \cdot F\left(t-t_{j}\right)
$$

with

$$
F\left(t-t_{j}\right)=\left\{1-\exp ^{\alpha^{2} \frac{\Lambda \cdot\left(t-t_{j}\right)}{\lambda^{2}}} \operatorname{erfc}\left(\frac{\alpha \sqrt{\Lambda \cdot\left(t-t_{j}\right)}}{\lambda}\right)\right\}
$$

An iterative procedure is used to determine the value of the heat transfer coefficient from the above equations.

The Dittus-Boelter correlation for rounded smooth channels was used to normalise the Nusselt number. $N u_{0}$ was based on the inlet flow conditions following the equation:

$$
N u_{0}=0.023 \cdot \operatorname{Re}^{0.8} \cdot \operatorname{Pr}^{0.3}
$$

\section{Heat transfer uncertainty analysis}

The error in the heat transfer measurements has been calculated considering the method described in Höcker [20]. It showed that the error can be minimised by adjusting measurement parameters as the model material and the dimensionless temperature $\mathrm{T}=\left(T_{L C}-T_{i}\right) /\left(T_{G}-T_{i}\right)$. In the present study, the heat transfer coefficients are of the order of $20 \mathrm{~W} / \mathrm{m}^{2} \mathrm{~K}$ to $200 \mathrm{~W} / \mathrm{m}^{2} \mathrm{~K}$. Using the method of Höcker [20], this leads to optimum dimensionless temperatures between $0.2<\mathrm{T}<0.4$. Thus it was chosen to set the different temperature at $T_{i} \approx 18^{\circ} \mathrm{C}, T_{G} \approx 70^{\circ} \mathrm{C}, T_{L C} \approx 32.7^{\circ} \mathrm{C}$, in order to obtain an average dimensionless temperature $\mathrm{T}=0.28$. The maximum error can be estimated to $\pm 8 \%$ on the heat transfer coefficient under the assumption that the heat transfer coefficient is constant during the experiment.

\section{RESULTS AND DISCUSSION}

The objectives of the present work are:

- To present complete heat transfer set of data in the straight legs and in the bend region of a two-pass internal cooling channel provided with $45 \mathrm{deg}$ rib arrangement.

- To relate the full surface and the area averaged heat transfer measurements for CFD code evaluation.

- To determine the combined influence of both the Reynolds number and the extraction, on the heat transfer distribution in a two-pass internal cooling channel.

\section{Flow characteristics}

The flow in the present passages have been described in literature. Chanteloup et al. [12] presented the flow in the channel with $0 \%$ extraction. Chanteloup et al. [13] showed the influence of the extraction on the flow characteristics. The readers are referred to these references for further details.

\section{Full surface heat transfer distribution}

The comparison of area-averaged heat transfer results between the present measurements and CFD calculations can give numerous discrepancies. The set of full surface heat transfer distribution can help to analyze these discrepancies. Furthermore, the accuracy of today's CFD codes in predicting heat transfer in cooling channels is increasing. It will lead in the near future to $3 \mathrm{D}$ heat transfer predictions to be used for cooling channel design. The present part aims at providing such a detailed full surface heat transfer distribution.

\section{Influence of extraction}

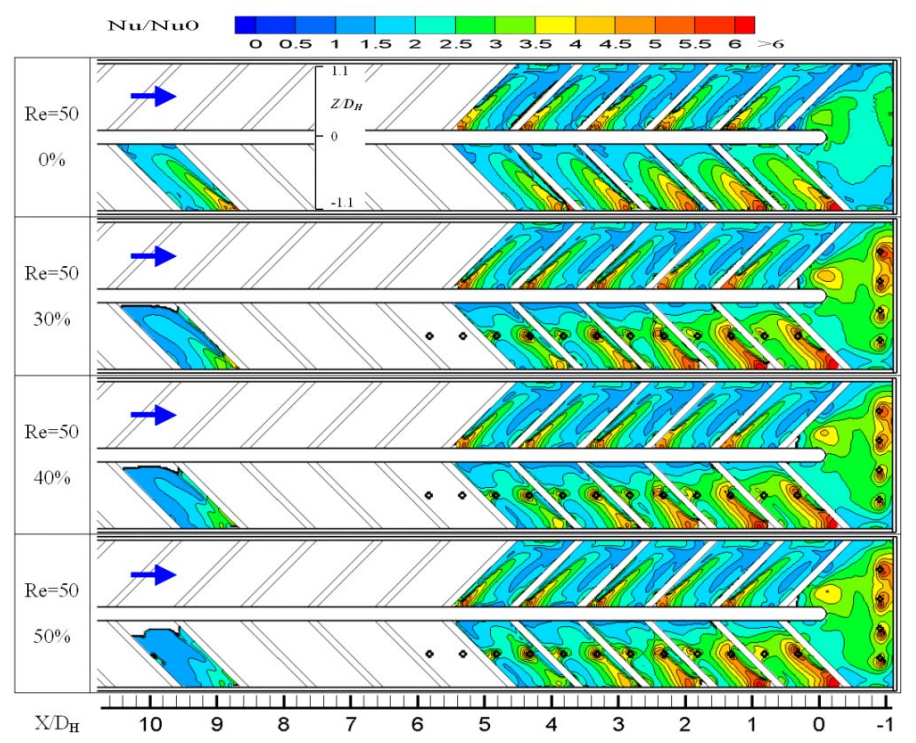

Figure 4: Bottom wall: influence of the extraction.

Figure 4 shows the full surface $\mathrm{Nu} / \mathrm{Nu}$ d distribution on the bottom wall of the baseline configuration, for a flow condition of $\mathrm{Re}=50000$ and for four extractions.

Upstream of the bend, the heat transfer distribution is typical of fully developed flow region in channels with $45 \mathrm{deg}$ 
rib arrangements. It has been described in details in Rau [10] and Chanteloup et al. [11]. For $C_{\text {extrac }}=0 \%$, the heat transfer distribution is quite repetitive from one rib module to another, indicating that it is in the fully developed region. In the last rib module upstream of the bend, the region of high heat transfer is more angled than in the other rib modules, indicating that the flow enters the bend region. The secondary flow seems to dominate the heat transfer distribution until the flow has entered the bend itself. Adding extraction does not seem to influence the heat transfer distribution upstream of the bend.

The bend region heat transfer distribution looks completely different to that of the $N u / N u_{0}$ ribbed region. In the $0 \%$ extraction case, no high heat transfer gradients occur, compared to the upstream ribbed region. $N u / N u_{0}$ values remain lower than 3.5. Nevertheless, two higher $N u / N u_{0}$ regions appear at the web tip and along the upstream part of the back wall $(0<Z<0.8)$.

In the bend, the extraction influences the heat transfer distribution. The contours global shape is the same as in the case with $0 \%$ extraction, but the mean level of heat transfer is higher. Figure 9 showed an increase of about 38\%. The two regions at the web tip and along the upstream part of the back wall are still present. A heat transfer increase takes place at every hole location. It is due to the decrease of the thermal boundary layer in the vicinity of the holes created by the extraction.

Downstream of the bend, the heat transfer levels are clearly higher than in the upstream leg. The upstream fully developed distribution shape is recovered from the first rib module downstream of the bend. In the $0 \%$ extraction case, the upstream leg level and shape seem to be reached after $10 \mathrm{D}_{\mathrm{H}}$, although the area-averaged value is still $10 \%$ higher as mentioned previously.

In the downstream leg, the extraction presence influences the heat transfer distribution. The U-shape high heat transfer region (due to the $45 \mathrm{deg}$ rib arrangement) is present in all the rib modules. The heat transfer increases around the holes in a same manner as in the bend. The $N u / N u_{0}$ levels decrease farther downstream in the leg due to the massflow extraction, but no evolution can be clearly noticed when modifying the extraction.

Note that at $X / D_{H}=10$, the extraction modifies the heat transfer distribution. $N u / N u_{0}$ values are higher as the extraction decreases, i.e. as the local massflow increases. Indeed, in this region, no extraction occurs anymore, and the local channel massflow dominates the heat transfer levels.

Figure 5 shows heat transfer distribution on the top, upstream and downstream sidewalls. Measurements at $\mathrm{Re}=50000$ are shown for $C_{\text {extrac }}=0 \%$ and $50 \%$. Other extractions are not plotted since the results are similar to the $50 \%$ extraction.

Figure 5 shows $\mathrm{Nu} / \mathrm{Nu}$. distribution on the top wall of the $C_{\text {extrac }}=0 \%$, for a flow condition of $\mathrm{Re}=50000$. The upstream heat transfer distribution is similar to the one of the bottom wall. This can be attributed to the symmetrical shape of the secondary flow field about the centre plane $Y=0.5$.

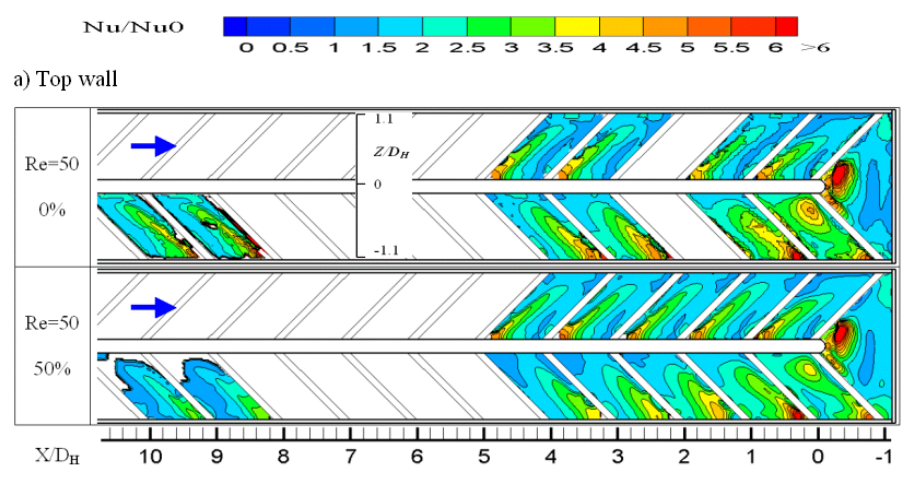

b) Upstream sidewall

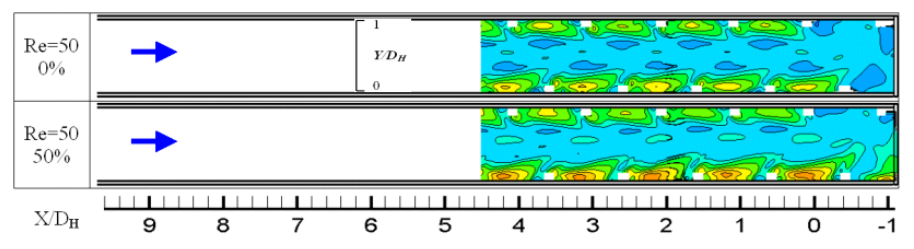

c) Downstream sidewall

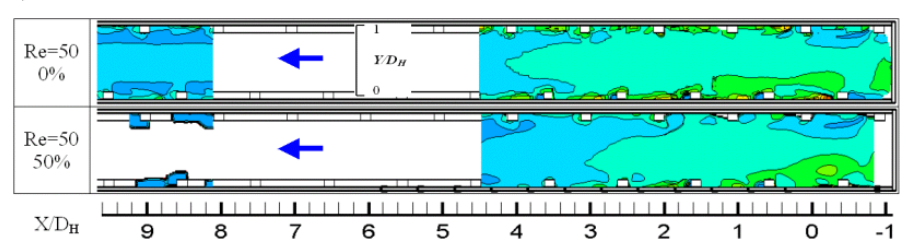

Figure 5:Top wall and sidewalls: influence of extraction.

The bend region heat transfer distribution is divided into two zones, $0>X>-0.6$ near the web tip, and $-0.6>X>-1.1$ near the back wall. The region $0>X>-0.6$ is a region with high heat transfer; $N u / N u_{0}$ is higher than 6 in the core of this region. It is due to the strong flow impact on the wall, which is shown in figure 4 of Chanteloup et al. [13]. The region $-0.6>X>-1.1$ has lower heat transfer values $\left(N u / N u_{0} \approx 1-1.5\right)$ and gradients are relatively low in this second region.

In the downstream leg, the heat transfer recovers from the bend effect less rapidly than on the bottom wall. The first downstream rib module shows a distribution shape different from the typical $45^{\circ}$ inclined rib shape. Two regions of high heat transfer $\left(N u / N u_{0}>5\right)$ are located at the rib root, near the outer wall and near the web tip. The heat transfer distributions in the rib modules further downstream are similar to that of the downstream rib modules of the bottom wall.

Adding extraction in the channel influences the heat transfer distribution on the top wall less than on the bottom wall. The $N u / N u_{0}$ contours are located approximately at the same place with or without extraction. The levels are also very similar. 
Figure 57 shows $\mathrm{Nu} / \mathrm{Nu} u_{0}$ distribution on the upstream sidewall for a flow condition of $\mathrm{Re}=50000$. The fully developed heat transfer distribution on this wall has been described in Chanteloup et al. [11]. In the case with $0 \%$ extraction, the heat transfer distribution is almost symmetrical versus the $Y=0.5$ plane. In the case with extraction, the heat transfer is higher near the bottom wall (provided with extraction) than near the top wall. It indicates the effect of the extraction on the secondary flow field. The effect of extraction is also noticeable as the flow approaches the bend. From $X=4$ to $X=-1$, $\mathrm{Nu} / \mathrm{Nu} u_{0}$ levels decrease near the top wall, whereas they increase near the bottom wall. Both effects compensate each other, giving a stable area average value.

Figure 5 shows $\mathrm{Nu} / \mathrm{Nu}$ distribution on the downstream sidewall for a flow condition of $\mathrm{Re}=50000$. The downstream sidewall is characterised by the turning flow impingement zone at approximately $X=0$. The heat transfer is slightly higher for the cases with extraction. Farther downstream, the flow recovers from the bend effect and the heat transfer reaches the upstream inner sidewall fully developed values. Note the heat transfer profile asymmetry (versus $Y=0.5$ plane), which occurs on the downstream sidewall. It is due to the flow field asymmetry induced by the extraction.

\section{Influence of Reynolds number}

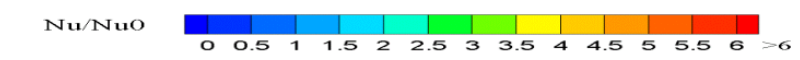

a) Bottom wall: $\mathrm{Re}=25000$

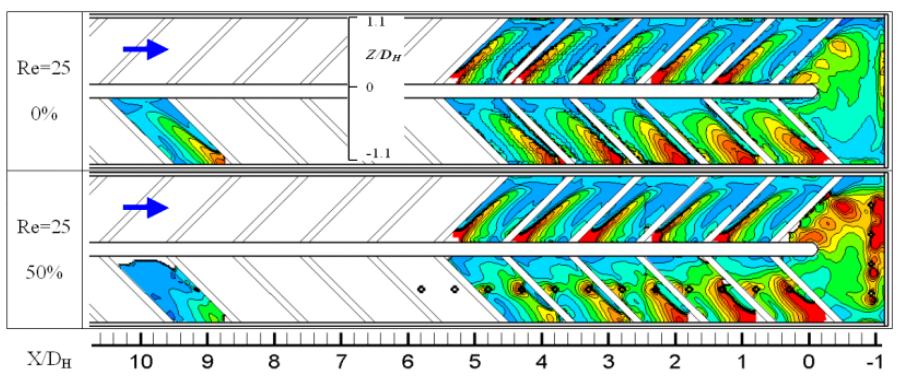

b) Bottom wall: $\mathrm{Re}=70000$

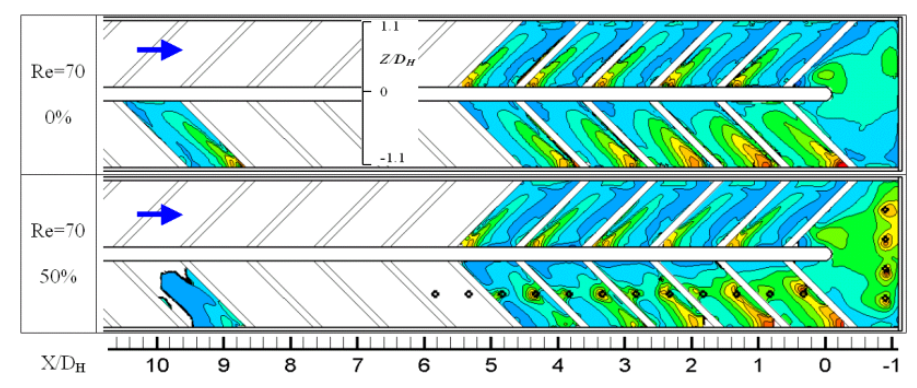

Figure 6: Bottom wall: Influence of Re and of $C_{\text {extrac }}$.

Bottom wall $\mathrm{Nu} / \mathrm{Nu} u_{0}$ results are plotted on Figure 6 for two extractions; $0 \%$ and $50 \%$. This figure in addition to Figure 4 gives a description of the influence of Reynolds number on the heat transfer full surface distribution. Note that the trends described in the present part are valid for all the channel walls.
The influence of Reynolds number is the same as given in Figure 8: the $\mathrm{Nu} / \mathrm{Nu} u_{0}$ ratios decrease as Re increases. Furthermore, the contour shapes are not modified by Re variation. This trend is valid at every measured location in the channel, except in the bend region. At $\mathrm{Re}=25000$, a high heat transfer area occurs downstream of the last bottom rib, from $Z=0.1$ to $Z=0.9$. Note that this area is responsible for the $48 \%$ heat transfer increase due to extraction in the upstream part of the bend. It might create high heat transfer gradients with thermal stresses in the bend region. This can become critical, as the bend region is an important part to homogeneously cool, and particularly in industrial gas turbines. Note that although not shown here, this difference at $\mathrm{Re}=25000$ does not occur on the top wall.

\section{Area averaged heat transfer results}

Area-averaged values are of prime interest as CFD code validation is concerned. Figure 7 shows $N u / N u_{0}$ areaaveraged values for the $0 \%$ extraction case, at $\mathrm{Re}=50000$. Area averages are done between each rib. Data are given versus the accumulated length on all the channel outer walls. One value is plotted for every rib module on the ribbed walls. Zones are plotted every $0.5 D_{H}$ on the sidewalls (one zone between two top wall ribs and the next zone $0.5 D_{H}$ downstream, between the next two bottom wall ribs). Dashed lines around $l / D_{H}=0$ represent the bend region.

It must be mentioned that area-averaged values are not plotted $10 D_{H}$ downstream of the bend. The gas temperature decreases along the channel (see Figure 3) and at $10 D_{H}$ downstream on the bend, locations of the surface cannot reach the liquid crystal temperature. This leads to blank measurements, which do not allow area heat transfer averaging over the full surface

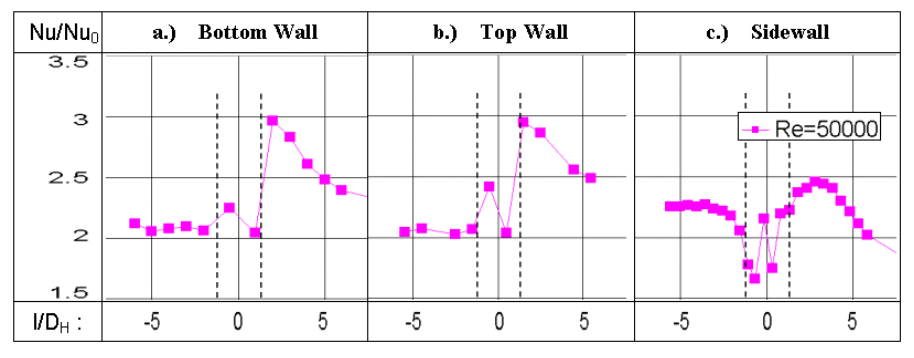

Figure 7: Area averaged $\mathrm{Nu} / \mathrm{Nu} u_{0}$ distribution on the channel walls.

The ribbed wall heat transfer distributions present three similar characteristics along the channel.

The $N u / N u_{0}$ values on the ribbed walls are stable in the upstream leg, indicating that the flow is fully developed. This stable value remains the same up to $1 D_{H}$ upstream of the bend. The heat transfer in the upstream leg does not seem to be influenced by the bend.

The ribbed wall $N u / N u_{0}$ values are strongly influenced in the bend itself. The bend influence is noticeable with heat transfer enhancement in the first half of the bend region, of 
$10 \%$ to $20 \%$ compared to the fully developed values. The area average results of the second half of the bend are approximately equal to the fully developed values. The fluctuations in the bend regions are larger on the top wall than on the bottom wall. This is due to the top wall ribs extending in the bend.

Downstream of the bend, the ribbed wall values recover from the bend effect. The heat transfer levels evolve in the same manner and the $N u / N u_{0}$ values are approximately equal for both ribbed walls. They reach a peak value in the first two ribs downstream of the bend, up to $50 \%$ higher than in the fully developed region. The heat transfer decreases farther downstream, as the flow recovers from the $180^{\circ}$ bend. Note that $10 D_{H}$ downstream of the bend, the heat transfer level is still $5 \%$ to $10 \%$ higher than in the fully developed region.

The outer smooth walls, which are the upstream outer sidewall, the bend back wall and the downstream outer sidewall, have a heat transfer distribution slightly different from the ribbed walls. The plateau value in the upstream leg is disturbed by the bend, up to $2.5 D_{H}$ from the back wall. It indicates that the flow undergoes the bend effect. The flow accelerates towards the web at the bend inlet, as shown in Chanteloup et al. [12], and the impinging flow strength on the outer wall shown in Chanteloup et al. [11] diminishes at the bend inlet. The upstream outer wall minimum value occurs in the corner between the sidewall and the back wall $\left(N u / N u_{0}=1.75\right)$. This is due to the recirculating cell in the upstream bend corner. The back wall is split into two zones; the upstream zone $(Z>0)$ and the downstream zone $(Z<0)$. The upstream zone heat transfer is $20 \%$ higher than in the fully developed region. The major part of the incoming flow impinges on the back wall in this region. The downstream part has a heat transfer level as high as the last zone of the upstream sidewall. Downstream of the bend, the outer wall heat transfer level increases from the downstream bend corner, where a recirculating cell takes place, to a maximum value at $l / D_{H}=2.5$ downstream of the back wall, where the turning flow impinges on the outer wall. The heat transfer values rapidly decrease to levels lower than the fully developed levels; $\mathrm{Nu} / \mathrm{Nu} u_{0}=1.6310 D_{H}$ downstream of the bend against 2.25 upstream of the bend. This behaviour is due to the symmetrical rib arrangement between both the upstream and downstream channel legs. The secondary flow acts on the outer walls in a different manner (see Chanteloup et al. [11]).

It should be mentioned that the outer wall area averaged values seem to be higher than the ribbed wall values, which is not the desired effect of a rib-equipped cooling channel. In fact, the ribs themselves are not taken into account in the area averaging. According to literature, taking into account the $45 \mathrm{deg}$ ribs increases the between ribs area average value by about $33 \%$. It produces full rib module area average values higher than the upstream sidewall values (e.g. $N u / N u_{0} \approx 2.1 * 1.33=2.8$ on the ribbed walls against $N u / N u_{0}=2.25$ on the sidewalls).
Present measurement results in the fully developed flow were compared to a correlation for $45 \mathrm{deg}$ rib-arrangements presented in Han et al. [3] (Han). The correlation was extrapolated beyond Han's test range $\left(0.047<e / D_{H}<0.078\right)$. The result from the present study is an average of measurements in the fully developed section of the first leg.

\begin{tabular}{|c|c|c|}
\hline $\boldsymbol{R e}=\mathbf{5 0 0 0 0}$ & Results & Han \\
\hline Str & 0.0091 & 0.0085 \\
\hline Sts outer & 0.0073 & 0.0067 \\
\hline Sts web & 0.0054 & 0.0067 \\
\hline
\end{tabular}

Table 2: Fully developed area average Stanton numbers compared to Han et al. [3] correlation.

Table 2 gives values of area-average Stanton number. Measurements were normalised by the projected area to compare with the correlations. Str, Sts outer and Sts web represent the ribbed, outer and web walls area average Stanton numbers respectively. Note that Han et al. [3] smooth wall values were obtained as the mean value of both smooth walls. Present heat transfer results and correlations are in agreement, taking into account the measurement and correlation uncertainties ( $\pm 8 \%$ and $\pm 10 \%$ respectively), and the blockage ratio differences between Han et al. [3] and the present geometries.

Influence of Reynolds number

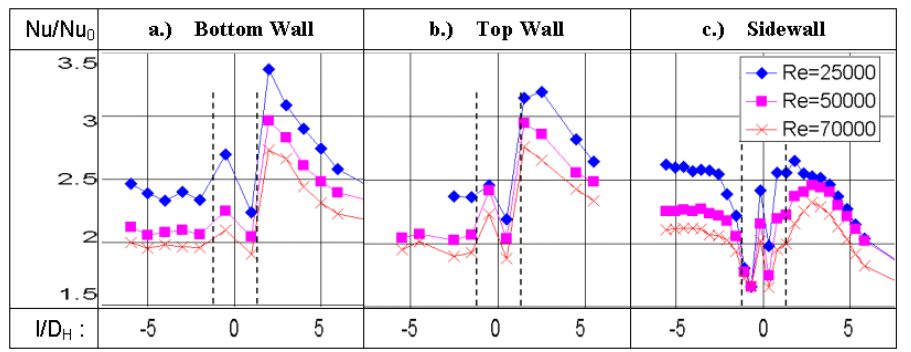

Figure 8: Influence of Reynolds number on the Area averaged $\mathrm{Nu} / \mathrm{Nu}$ distribution.

In Figure 8, the heat transfer distribution at $\mathrm{Re}=25000$ and $\mathrm{Re}=70000$ are superimposed on the results of Figure 7. The area averaged heat transfer results evolve in a similar way for all three Re tested. However at every location in the channel, the $\mathrm{Nu} / \mathrm{Nu} u_{0}$ values decrease as Re increases. Liou et al. [21] and Liou et al. [22] showed a similar trend. Note that due to the evolution of the Dittus-Boelter Nusselt number, increasing with Re number, $N u$ values increase with the Reynolds number.

\section{Influence of extraction}

Extracting a part of the flow from the channel modifies the heat transfer distribution along the channel. Figure 9 gives areaaveraged heat transfer results on the channel walls at three Reynolds numbers. Cases with extraction were added to the $0 \%$ extraction results plotted in Figure 8. 


\begin{tabular}{|c|c|c|c|}
\hline $\mathrm{Re}$ & Bottom & Top & Outer \\
\hline $25 \mathrm{k}$ & $\mathrm{a} 1$ & $\mathrm{~b} 1$ & $\mathrm{c} 1$ \\
\hline $50 \mathrm{k}$ & $\mathrm{a} 2$ & $\mathrm{~b} 2$ & $\mathrm{c} 2$ \\
\hline $70 \mathrm{~K}$ & $\mathrm{a} 3$ & $\mathrm{~b} 3$ & $\mathrm{c} 3$ \\
\hline
\end{tabular}

Table 3: definition of plots in Figure 9

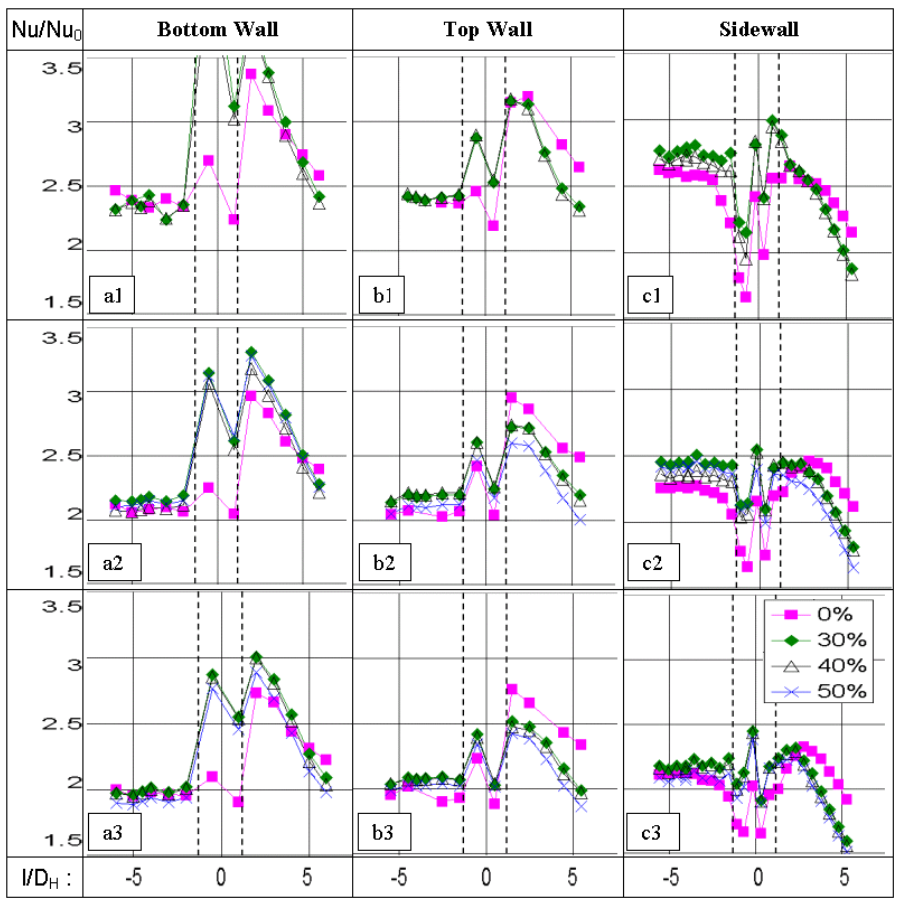

Figure 9: Influence of extraction on the Area averaged $\mathrm{Nu} / \mathrm{Nu}$ distribution.

The upstream leg distribution on all walls is not clearly modified by the extraction. Although the flow field was shown to be influenced by the extraction in this region, it did not influence the area averaged in the upstream leg.

In the bend region and downstream of the bend, the extraction modifies the heat transfer on all walls.

On the bottom wall, which is provided with the extraction holes, the bend region $N u / N u_{0}$ distribution is strongly increased by the extraction. In the upstream part of the bend wall, $\mathrm{Nu} / \mathrm{Nu} u_{0}$ values are $48 \%, 38 \%$ and $33 \%$ higher than in the $0 \%$ extraction case, for $\mathrm{Re}=25000,50000$ and 70000 , respectively. $\mathrm{Nu} / \mathrm{Nu} u_{0}$ decreases downstream of the bend. The levels are higher than at $0 \%$ extraction immediately downstream of the bend, and they are lower downstream of $l / D_{H}=4$. Upstream of $l / D_{H}=4$, the presence of the holes provides a heat transfer enhancement, which is enough to obtain a $N u / N u_{0}$ level higher than in the $0 \%$ case. Downstream of $l / D_{H}=4,60 \%$ of the total extracted massflow has already left the channel, and the enhancement due to the hole is not enough to obtain the heat transfer levels of the $0 \%$ case.

On the top wall, which is not equipped with extraction holes, the heat transfer levels are also influenced by the extraction. In the bend region, the $N u / N u_{0}$ levels are similar for $C_{\text {extrac }}=0 \%$ to $50 \%$. Note that in the bend region, for all the extractions, only $20 \%$ of the total extracted massflow has left the channel. In the downstream leg, the heat transfer levels of cases with extraction are lower than in the $0 \%$ extraction case. The heat transfer decrease due to the massflow loss along the channel, is not compensated by the heat transfer enhancement around the extraction holes (see Figure 4. One consequence is that the $N u / N u_{0}$ differences are greater than $20 \%$, between the top and the bottom walls in the cases with extraction.

On the outer walls, the presence of extraction improves the heat transfer, in the near upstream bend region, and in the bend region. $\mathrm{Nu} / \mathrm{Nu} u_{0}$ values do not collapse as the flow enters the bend, and the back wall values are also higher than for $C_{\text {extrac }}=0 \%$. This can be attributed to the extraction impact on the recirculating cell structure located in the upstream bend corner. The flow is accelerated in the bottom wall region. Thus the impingements on the walls are stronger than in the case with no extraction (see figure 4 of Chanteloup et al. [13]). Downstream of the bend for $l / D_{H}<2.5$, the heat transfer is higher in the cases of extraction. This is due to the flow impingement modification in strength and location, just downstream of the bend. Farther downstream, the heat transfer with extraction is lower than for the $0 \%$ extraction case. The explanation is the same as for the top wall; the heat transfer decrease due to the massflow loss along the channel is not compensated by the heat transfer enhancement around the extraction holes.

The main conclusion from this data is that the influence of the extraction is noticeable compared to the case with no extraction. However the various extraction rates studied give line plots that are superimposed. This indicates that the Nusselt number distribution does not seem to depend on the extraction rate in the ranges of Reynolds number and extraction studied. It can be explained as follow: Byerley et al. [7] showed that the suction ratio (SR) has a great impact on the heat transfer distribution around the holes. Tests showed that SR increases for a particular hole as $C_{\text {extrac }}$ increases. The heat transfer enhancement associated with the SR increase, seem to compensate the heat transfer fall associated with higher channel massflow loss.

Several references led to similar conclusions with 90deg rib arrangements. Thurman et al. [9] studied a triple-pass channel, with eight holes in the first pass and with a suction ratio $S R=4.9$. It found extraction to have appreciable effects on the full surface heat transfer distribution. Shen et al. [8] used a single-pass channel with five holes and with $S R=1.85$ to 5.07 . It showed that the extraction raised the averaged heat transfer value from the $0 \%$ extraction ribbed wall by about $25 \%$, independently of the suction ratio. Ekkad et al. [23] used a twopass channel with 20 holes in both the upstream and downstream leg, and a $S R=0.8$. It found that the extraction did not modify the area-averaged $N u / N u_{0}$ ratios. This conclusion 
is thought to be due to the suction ratio differences with the other references and with the present study ( $S R=6$ in the bend region and $6<S R<12$ in the downstream leg).

It must be mentioned that for the previously presented results, $N u_{0}$ was based on the channel inlet conditions. The Nusselt number can be normalised by the Dittus-Boelter Nusselt number based on the local channel flow conditions, in order to isolate the impact of the extraction. Table 4 shows Nusselt numbers normalised by local Dittus-Boelter Nusselt numbers. The local Dittus-Boelter Nusselt numbers were calculated using the channel local massflow plotted in figure 3 of Chanteloup et al. [13]. Values given in Table 4 were extracted from the bottom wall $5^{\text {th }}$ rib module downstream of the bend. The results show that with a normalisation based on local flow properties, the Nusselt number increases as the extraction increases, i.e. as the suction ratio increases.

\begin{tabular}{|c|c|}
\hline Total Extraction & $\begin{array}{c}\mathbf{5}^{\text {th }} \text { rib } \\
N u / N \nu_{0 \_ \text {local }}\end{array}$ \\
\hline $0 \%$ & 2.3 \\
\hline $30 \%$ & 2.8 \\
\hline $40 \%$ & 3 \\
\hline $50 \%$ & 3.3 \\
\hline
\end{tabular}

Table 4: Bottom wall $5^{\text {th }}$ downstream rib module Nusselt number normalized by local Dittus-Boelter Nusselt number.

\section{Heat transfer gradients}

A better knowledge of the two-dimensional heat transfer distribution on the coolant channel surfaces can improve the cooling efficiency of the internal cooling system. They can moreover reduce thermal stresses in the blade material. In the present part, heat transfer gradients in spanwise and streamwise directions are given. They can provide useful information on the manner of using the coolant channels, in order to achieve homogeneous temperature in the blade.

The following figures show heat transfer results normalised by the full surface area averaged Nusselt number ( $\left.N=N u_{\text {zone }} / N u_{\text {full_surface }}\right)$. This normalization has not been used so far in the present report. This normalisation compares every interrogation point Nusselt number with the full surface area averaged value. Values of $1,>1$ or $<1$ in this normalization mean that the Nusselt number of the interrogated area is respectively equal, greater or lesser than the full surface area averaged Nusselt number. This normalisation allows comparing spanwise and streamwise $N u / N u_{0}$ gradients for various Reynolds numbers or extractions, although full surface $\mathrm{Nu} / \mathrm{Nu} u_{0}$ values are different.

\section{Influence of Reynolds number}

The surfaces plotted were divided into 10 zones equally distributed along the spanwise $(Z)$ or channel height $(Y)$ directions. For each zone, an area average Nusselt number was calculated, and normalised by the full surface area averaged
Nusselt number. Figure 10 gives the zone definitions for spanwise and streamwise directions.

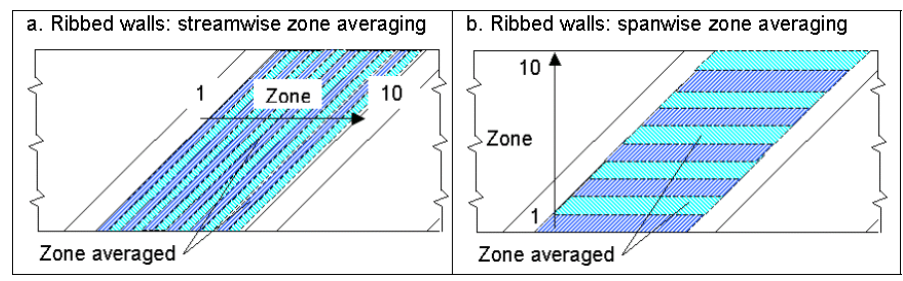

Figure 10: Zone definition for gradient graphs.

Figure 11 shows the cross-stream distribution of $\mathrm{Nu}$ in the 4th upstream rib module and in the 4th downstream rib module, for the $0 \%$ extraction case. The three Reynolds numbers tested are plotted in the figure.

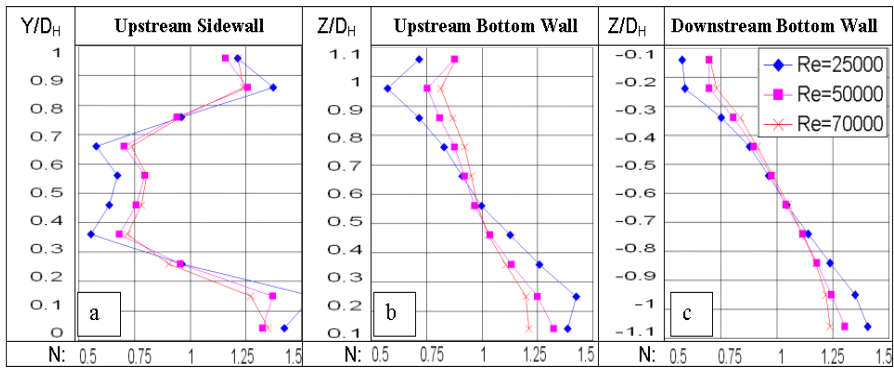

Figure 11: Cross-stream heat transfer gradients: Influence of Reynolds number.

Figure 119 shows the heat transfer distribution versus the channel height on the sidewall. The heat transfer distribution is nearly symmetric along the centreline $Y=0.5$. This confirms the similar influence of both ribbed walls, already noted in Figure 5. High heat transfer coefficient gradients occur on the sidewall. Nu values fluctuate by $80 \%$ of the $N u$ full surface area averaged value in one third of the channel height (between zone $10-20 \%$ and $30-40 \%$ ). Gradients are dependent on the Reynolds number. They increase as $\operatorname{Re}$ decreases. Note that the distribution is not completely symmetrical around $Y=0.5$. This is due to the zone definition, which includes a top rib without including a bottom rib. Indeed, an area of low heat transfer, located just above the bottom rib (see $0>Y>0.3$ in Figure 5), is not taken into account. This increases the values slightly for $Y<0.3$ compared to $Y>0.7$.

Figure 11, shows the heat transfer gradients on the upstream leg bottom wall. The zone was chosen adjacent to the sidewall zone shown in Figure 11a.

A region of high heat transfer is present at the rib root, near the web $(0.1>Z>0.3)$. The area between $10-20 \% D_{H}$ $(0.2>Z>0.3)$ reaches a value of 1.4 times the area averaged $N u$ value. It is due to the U-shape high heat transfer zone induced by vortex structures in $45 \mathrm{deg}$ rib arrangements. The vortex influence shown in Chanteloup et al. [11] is also noticeable near the outer wall. Indeed, the impact on the outer wall reveals a positive gradient between the regions $80-90 \%$ and $90-100 \%$. 
Between $10 \%$ and $90 \%(0.2>Z>1)$, the heat transfer distribution is nearly linear for all three Reynolds numbers, with a slope depending largely on the Re. The steepest slope occurs for $\mathrm{Re}=25000$, with plot extreme values reaching $-40 \%$ to $+40 \%$ of $N u_{\text {full_suface }}$.

Figure 11. shows the heat transfer gradients on the downstream leg bottom wall. Note that due to symmetrical rib arrangement $Z / D_{H}$ is negative. The heat transfer is very similar to the upstream bottom wall of Figure 11,. The same gradients take place with the same maxima. The ribs distribute the heat transfer in the same manner as in the upstream leg, even if the flow is still recovering from the bend effect.

Conclusions of this graph are that the heat transfer gradients on the ribbed walls are higher as Reynolds number decreases; The heat transfer in the straight channels of the present geometry is symmetrically distributed among the channel centreline.

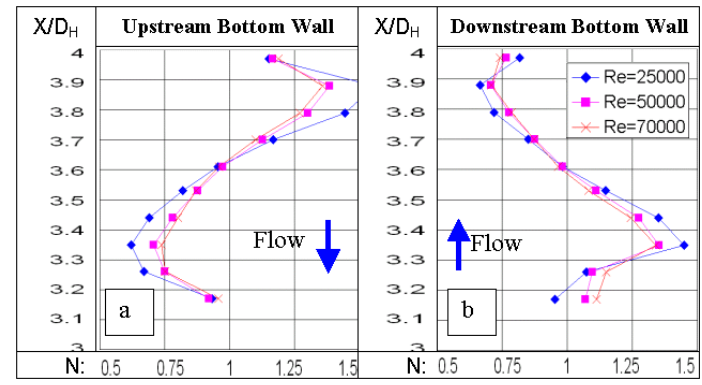

Figure 12: Streamwise heat transfer gradients: Influence of Reynolds number.

Figure 12 shows bottom wall heat transfer gradients in the streamwise direction. They are plotted in the same rib modules as in Figure 11P and Figure 11,. The surfaces plotted were decomposed into 10 zones parallel to the ribs equally distributed along the streamwise $(X)$ direction. Note that no value is available for $3<X<3.15$, since no measurements were performed on the rib.

In the upstream leg, streamwise $N$ gradients are as high as spanwise gradients. Values for $\mathrm{Re}=25000$ from $-40 \%$ to $+60 \%$. Values are symmetrically distributed around the rib module centre, with $40 \%$ of the values higher, and $40 \%$ lower than 1 . It can be noticed that immediately downstream of the rib $(X<4)$, gradients are slightly higher than downstream of the rib module centre $(X<3.5)$.

In the downstream leg, the gradients are similarly located as in the upstream leg. The highest values take place downstream of the rib $(X>3.15)$, and the lowest value upstream of the next rib $(X<4)$. However, the flow recovery from the bend effect creates some differences with the upstream distribution. $40 \%$ of the values are lower than 1 , whereas $50 \%$ are higher than 1 . The gradients are higher and their variation is greater than in the upstream leg.

Note that in both the upstream and downstream legs, the highest heat transfer zones occur downstream of the rib, and that the rib is also a zone of high heat transfer. This can lead to thermal stresses in the vicinity of the ribs.

A global trend can be drawn from the plots given in Figure $11^{\text {and }}$ angure 12. As Re increases the gradients diminish, and the $N$ values tend to 1 . One explanation could be that the ribs, which are geometrical singularities at low Re, tend to become global geometrical characteristics at high Re. The rib arrangement might be compared to a roughness at high Reynolds numbers, yielding a homogeneous heat transfer distribution.

\section{Influence of extraction}

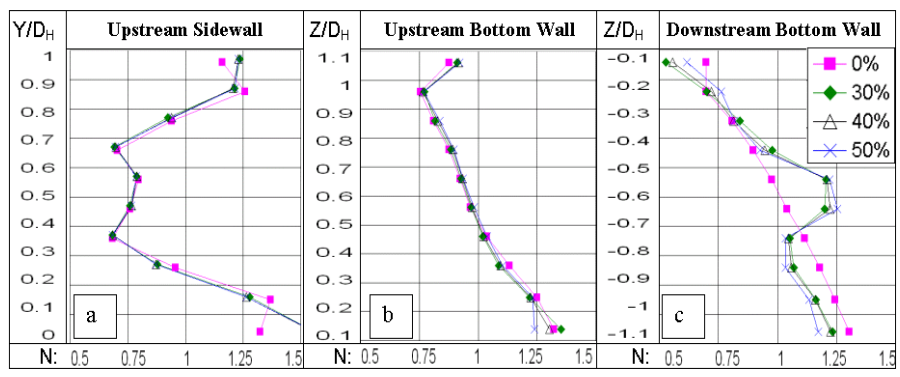

Figure 13: Cross-stream heat transfer gradients: Influence of extraction.

Figure 13 shows the influence of extraction on the same zones as in Figure 11. Results for $\mathrm{Re}=50000$ flow condition are plotted. Note that the $C_{\text {extrac }}=0 \%$ case was plotted in Eigure 11. Note also that full surface $N u / N u_{0}$ values for $C_{\text {extrac }}=0 \%$ to $50 \%$ are approximately equal at the location of the zones plotted (see Figure 9). Thus gradient values relative to extraction also give information on the heat transfer values.

Upstream of the bend, the line plots are globally superimposed, for every extraction in Figure 13 and Figure 13 b. Slight differences occur in the vicinity of the ribbed walls in Figure 13. The cross-stream heat transfer gradients in the upstream leg do not seem to be influenced by the extraction occurring in the bend and in the downstream leg.

Downstream of the bend, the extraction influences the spanwise heat transfer gradients. A high increase of $N$ values takes place around the hole locations $(Z=-0.6)$. Values are up to $25 \%$ higher than in the case without extraction. This increase is compensated in the high heat transfer region near the downstream sidewall. Values are $10 \%$ to $15 \%$ lower in the cases with extraction in the region $-0.7>Z>-1.1$. In the low heat transfer region near the web $(-0.1>Z>-0.4)$, the $N$ values are equal whatever the extraction.

Figure 14 shows the influence of extraction on the same zones as in Eigure 12. Results for $\mathrm{Re}=50000$ flow condition are plotted.

In the upstream leg, the $0 \%$ extraction case is slightly different from the extraction cases. The $N$ gradients and values are similar, but the $0 \%$ extraction values are shifted by $0.1 D_{H}$ towards the upstream rib. This difference is compensated by lower gradients in $3.4>X>3.8$. Upstream of the next downstream rib $N$ values are approximately equal. 
In the downstream leg, the influence of the extraction on the streamwise distribution is smaller than in the spanwise direction. The extraction shifts the heat transfer distribution of $0.1 D_{H}$ towards the downstream rib. The hole locations are not clearly identifiable. Indeed, the two rib module holes are not located in the same sub-zone. The heat transfer enhancement around the hole entrance has a lower impact on the results.

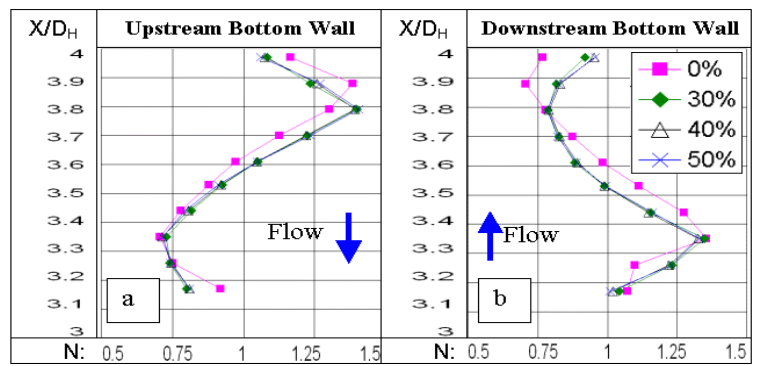

Figure 14: Streamwise heat transfer gradients: Influence of extraction.

\section{Recovery from the bend effect}

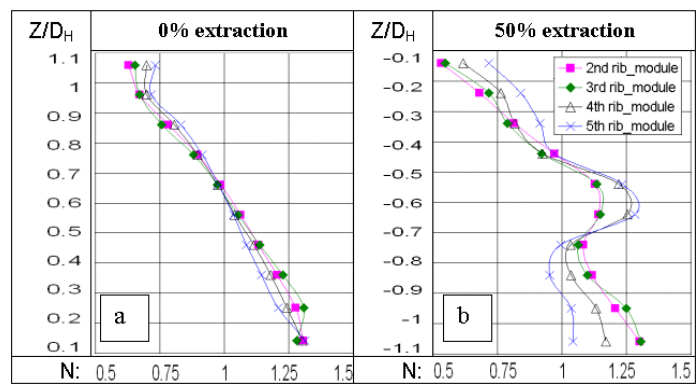

Figure 15: Spanwise heat transfer gradient development downstream of the bend.

Figure 15 shows the evolution of the $N$ values downstream of the bend, as the flow recovers from the bend effect. Bottom wall rib modules are plotted from the second to the fifth rib modules downstream of the bend. Note that the fourth rib module was plotted from Eigure 11 to Eigure 14.

For $C_{\text {extrac }}=0 \%$, the distance to the bend does not seem to have an impact on the $N$ distribution. Although the full surface area averaged values are very different from one rib module to another (see Figure 7), $N$ values and gradients are equal. The evolutions of the plots are the same as described in Figure 11.

For $C_{\text {extrac }}=50 \%$, the $N$ distribution is dependent on the distance to the bend. The heat transfer enhancement around the hole entrance has less impact in the rib modules just downstream of the bend than in the farther downstream rib modules. This is due to the high streamwise velocity region near the downstream sidewall. This high velocity flow increases the heat transfer at the rib root, diminishing the hole impact on the full surface heat transfer value. As the flow redevelops farther downstream, the impact of the high velocity region decreases, giving higher relative influence of the hole entrance region.

\section{CONCLUSIONS}

Heat transfer measurements were obtained in two-legged blade coolant passage models with ribs orientated 45 deg to the passage. A comparison is presented between two similar configurations; one is a baseline, while the second one is provided with bleeding holes, simulating the holes for external film cooling of blades. It was possible to extract full surface and area averaged heat transfer results on all the outer walls of the models.

On the ribbed walls, the $N u / N u_{0}$ values are stable in the upstream leg, they increase by $10 \%$ in the bend region, reach a peak downstream of the bend, and decrease to values close to the upstream fully developed values far downstream of the bend. They compare well with correlations found in literature.

Varying the Reynolds number influences the heat transfer results. $N u$ values decrease as Re decreases, whereas $N u / N u_{0}$ increase. The variations of $N u / N u_{0}$ in various regions of the channel are also more important as Re decreases. The full surface heat transfer results show an increase of $\mathrm{Nu} / \mathrm{Nu}$ values over the entire surfaces whereas contour shapes remain the same in all the measured zones. An exception must be made in the bend region, where some details of distribution are modified at $\mathrm{Re}=25000$.

The effect of extraction, compared to the $0 \%$ extraction case, is dependent on the channel region. In the upstream leg, the influence of extraction is hardly noticeable. In the bend region and downstream of the bend, the heat transfer is highly increased on the wall provided with extraction holes. The improvement of area-averaged values is mainly due to a heat transfer enhancement in the vicinity of the hole entrance. A slight effect occurs on the walls without extraction holes. Only a slight dissymmetry of the full surface heat transfer distribution is introduced by the extraction. It is due to the dissymmetry of the flow shown in previous works relating flow measurements.

Varying the extraction from $30 \%$ to $50 \%$ of the inlet massflow do not show any variation in the $N u / N u_{0}$ results, once $N u_{0}$ is based on the channel inlet flow conditions.

Typical zones on the ribbed walls and on the sidewalls were divided in sub-zones to show the variations of the streamwise and cross-stream variations of heat transfer. High gradients occur in both directions and it might be interesting to consider these gradients in coolant channel design. As Reynolds number increases, gradients tend to decrease and heat transfer is homogenised over the surface. The extraction influences the gradients mainly in the downstream leg, emphasising the heat transfer enhancement around the hole entrance.

Note that the extraction effects are less important on the heat transfer results than on the flow results presented in Chanteloup et al. [13]. However the heat transfer is a consequence of the flow distribution. Thus the flow distribution should also be considered in order to provide good heat transfer CFD predictions. 


\section{ACKNOWLEDGMENTS}

This study was funded by the Swiss Office of Science in cooperation with the BriteEuram Internal Cooling of Turbine Blades project (contract number: BRPR-CT97-0600, project number: BE97-4022).

\section{NOMENCLATURE}

$\mathrm{X} \quad$ Cartesian coordinate in axial duct direction

$\mathrm{Y} \quad$ Cartesian coordinate in cross duct direction

Z Cartesian coordinate in horizontal duct direction

1 Accumulated length

$\mathrm{U}_{\mathrm{b}} \quad$ Bulk mean-velocity

$\mathrm{D}_{\mathrm{H}} \quad$ Hydraulic diameter $\mathrm{D}_{\mathrm{h}}=100 \mathrm{~mm}$

P Rib pitch

e Rib height

$\mathrm{C}_{\text {extrac }}$ Ratio between the channel inlet massflow and the total extracted massflow

SR Suction Ratio, average hole velocity divided by passage average velocity

$\alpha \quad$ Heat transfer coefficient

$\lambda \quad$ Plexiglas thermal conductivity

$\Lambda=\lambda /\left(\rho \cdot C_{p}\right) \quad$ Plexiglas thermal diffusivity

$\mathrm{T}=\left(T_{L C}-T_{i}\right) /\left(T_{G}-T_{i}\right) \quad$ dimensionless temperature

$\mathrm{Nu} \quad$ Nusselt number

$N=N u_{\text {zone }} / N u_{\text {full_surface }} \quad$ Sub-zone Nusselt number normalised by the

full surface area averaged Nusselt number

$S t=N u /(\operatorname{Re} \cdot \operatorname{Pr}) \quad$ Stanton number

Bottom wall wall at $Y=0$

Top wall wall at $Y=1$

Back wall wall at $X=-1.1$

Upstream sidewall wall at $Z=1.1$

Downstream sidewall wall at $Z=-1.1$

\section{REFERENCES}

1. Mochizuki, S., Murata, A. and Fukunaga, M. (1997). Effects of rib arrangements on pressure drop and heat transfer in a rib-roughened channel with a sharp 180 deg turn. Journal of Turbomachinery, 119, 3, 610-616.

2. Han, J.C., Zhang, P. and Lee. (1991). Augmented heat transfer in square channels with parallel, crossed, and V-shaped angled ribs. Journal of Heat, 113 January 1991, 590-596.

3. Han, J.C. and Park, J.S. (1988). Developing heat transfer in rectangular channels with rib turbulators. Journal of Heat and Mass Transfer, 31 1988, 183-195.

4. Han, J.C. and Chandra, P.R., Local Heat/Mass Transfer and Pressure Drop in a Two-Pass Rib-Roughened Channel for Turbine Airfoil Cooling. 1987, Lewis Research Center NASA.

5. Wang, Z., Ireland, P.T., Kohler, S.T. and Chew, J.W. (1996). Heat transfer measurements to a gas turbine cooling passage with inclined ribs. Proceedings of the International Gas Turbine \& Aeroengine Congress \& Exhibition. Birmingham, UK. 1996. 96-GT-542.

6. Rau, G., Cakan, M., Moeller, D. and Arts, T. (1998). The effect of periodic ribs on the local aerodynamic and heat transfer performance of a straight cooling channel. Journal of Turbomachinery, 120 2, 368-375.

7. Byerley, A.R., Jones, T.V. and Ireland, P.T. (1992). Internal cooling passage heat transfer near the entrance to a film cooling hole: Experimental and computational results. Proceedings of the International Gas Turbine \& Aeroengine Congress \& Exhibition. Cologne, Germany. 1992. 92-GT-241.

8. Shen, J.R., Wang, Z., Ireland, P.T. and Jones, T.V. (1996). Heat transfer enhancement within a turbine blade cooling passage using ribs and combinations of ribs with film cooling holes. Journal of Turbomachinery, 118 July 1996, 428-434.

9. Thurman, D. and Poinsatte, P. (2001). Experimental heat transfer and bulk air temperature measurements for a multipass internal cooling model with ribs and bleed. Journal of Turbomachinery, 123 January 2001, 90-96.
10. Rau, G. (1998). Einfluss der Rippenanordnung auf das Strömungsfeld und den Wärmeübergang in einem Kühlkanal mit quadratischem Querschnitt. In: PHD Thesis (Technischen Universität Darmstadt), Vol. D17.

11. Chanteloup, D., Juaneda, Y. and Bölcs, A. (2002). Combined 3D flow and heat transfer measurements in a 2-pass internal coolant passage of gas turbine airfoils. Proceedings of the ASME Turbo Expo 2002. Amsterdam, The Netherlands. 2002. GT-2002-30214.

12. Chanteloup, D. and Bölcs, A. (2001). Particle image velocimetry investigation of the flow characteristics in two-leg internal coolant passages of gas turbine airfoils. Journal of Power and Energy, IMechE, 215 No A6, 743-752.

13. Chanteloup, D. and Bölcs, A. (2002). Flow characteristics in 2-leg internal coolant passages of gas turbine airfoils with film cooling hole ejection. Journal of Turbomachinery. 124, 3. 499-507.

14. Chanteloup, D. and Bölcs, A. (2002). Flow characteristics in 2-leg ribbed internal coolant passages of gas turbine airfoils with turning vane and film cooling hole ejection. Proceedings of the The 9th of International Symposium on Transport Phenomena and Dynamics of Rotating Machinery. Honolulu, Hawaii, USA. 2002.

15. Wang, Z., Gillepsie, D.R.H. and Ireland, P.T. (1996). Advances in heat transfer measurements using liquid crystals. In: Turbulent Heat Transfer (Engineering Foundation), 1-25. San Diego.

16. Ekkad, S.V. and Han, J.C. (1995). Local heat transfer distributions near a sharp $180^{\circ}$ turn of a two-pass smooth square channel using a transient liquid crystal image technique. Journal of Flow Visualisation and Image Processing, 2, 285-297.

17. Vogel, G. and Bölcs, A. (2000). A novel digital image processing system for the transient liquid crystal technique applied for heat transfer and film cooling measurements. Proceedings of the International Symposium on Heat Transfer in Gas Turbine Systems. Izmir, Turkey. 2000.

18. Wang, Z. (1991). The application of thermochromic liquid crystals to detailed turbine blade cooling measurements. In: Thesis (Department of Engineering Science, Oxford).

19. Vogel, G. and Weigand, B. (2001). A new evaluation method for transient liquid crystal experiments. Proceedings of the National Heat Transfer Conference. Anaheim, California, USA. 2001. ,NHTC01-1511.

20. Höcker, R. (1996). Optimization of transient heat transfer measurements using thermochromic liquid crystals based on an error estimation. Proceedings of the International Gas Turbine \& Aeroengine Congress \& Exhibition. Birmingham, UK. 1996. 96-GT-235.

21. Liou, T.-M. and Kao. (1988). Symmetric and asymmetric turbulent flows in a rectangular duct with a pair of ribs. Journal of Fluids Engineering, 110 1988, 373-379.

22. Liou, T.-M., Chang and Hwang. (1990). Experimental and computational study of turbulent flows in a channel with two pairs of turbulence promoters in tandem. Journal of Fluids Engineering, 112 1990, 302-310.

23. Ekkad, S.V., Yizhe Huang and Han, J.C. (1998). Detailed heat transfer distributions in two-pass square channels with rib turbulators and bleed holes. International journal of heat and mass transfer, 41 23, 3781-3791. 